\title{
Thyroid Ultrasound-Guided Fine-Needle Aspiration: The Positive Influence of On-Site Adequacy Assessment and Number of Needle Passes on Diagnostic Cytology Rate
}

\author{
Elizabeth J. de Koster ${ }^{\mathrm{a}, \mathrm{b}}$ Jakob W. Kist ${ }^{\mathrm{b}}$ Menno R. Vriens ${ }^{\mathrm{b}}$ \\ Inne H.M. Borel Rinkes ${ }^{b}$ Gerlof D. Valk ${ }^{c}$ Bart de Keizer ${ }^{d}$ \\ a Department of Radiology and Nuclear Medicine, Radboud University Medical Center, Nijmegen, and \\ Departments of ${ }^{b}$ Surgical Oncology and Endocrine Surgery, ' Endocrinology and d Nuclear Medicine and Radiology, \\ University Medical Center, Utrecht, The Netherlands
}

\section{Key Words}

Thyroid · Fine-needle aspiration - Specimen adequacy .

Image-guided intervention - Diagnostic accuracy

\begin{abstract}
Objective: Nondiagnostic cytology is the most important limitation of thyroid ultrasound-guided fine-needle aspiration (US-FNA). This study aimed to identify factors associated with the adequacy rate of thyroid US-FNA. Study Design: Consecutive thyroid US-FNAs (2006-2013) were retrospectively included. Attending radiologists, radiology fellows and radiology residents performed US-FNA, usually involving 2-3 needle passes. In more recent years, rapid onsite adequacy assessment (ROSAA) was performed to ensure specimen adequacy. US characteristics, procedural variations and cytology results were extracted from US and pathology reports and statistically evaluated. Results: Diagnostic cytology was obtained in $64.6 \%$ of 1,381 thyroid USFNAs. Factors associated with nondiagnostic cytology were ROSAA (74.6\% diagnostic cytology, OR $0.55,95 \% \mathrm{Cl} 0.42-$ $0.71), \geq 3$ clinic visits for US-FNA of the same thyroid nodule (54.7\%, OR 1.56, 95\% Cl 1.16-2.10) and increased intranodular vascularization (51.8\%, OR 1.73, 95\% Cl 1.17-2.57). With ROSAA, an increasing number of needle passes demon-
\end{abstract}

\section{KARGER}

E-Mail karger@karger.com www.karger.com/acy
(C) 2016 The Author(s) Published by S. Karger AG, Basel 0001-5547/16/0601-0039\$39.50/0

This article is licensed under the Creative Commons AttributionNonCommercial-NoDerivatives 4.0 International License (CC BY NC-ND) (http://www.karger.com/Services/OpenAccessLicense) Usage and distribution for commercial purposes as well as any distribution of modified material requires written permission. strated improving adequacy rates. The adequacy rate was not operator-dependent. Conclusion: This study demonstrates that ROSAA improves the adequacy rate of thyroid US-FNA. Without ROSAA, we recommend performing at least 3 needle passes. Less diagnostic cytology is obtained from nodules with increased intranodular vascularization or from those undergoing US-FNA $\geq 3$ times.

(c) 2016 The Author(s)

Published by S. Karger AG, Basel

\section{Introduction}

The prevalence of thyroid nodules on ultrasound (US) is reported to be as high as $30-70 \%$. As only $5 \%$ harbor a malignancy, fine-needle aspiration (FNA) is essential for their evaluation [1-4]. Adequate cytological diagnoses provided by FNA have resulted in a reduction of futile surgeries for benign thyroid nodules of up to $50 \%[1,2,5]$.

Although safe and cost-effective, the most important limitation of thyroid FNA is its high rate of nondiagnostic cytology with reported rates of up to $34 \%$ [1, 2, 6-11]. The established definition for adequate cytology is the presence of at least 6 groups of follicular cells, each containing 10-15 cells, preferably obtained from at least 2 aspirates of a nodule $[2,12,13]$. Nondiagnostic cytology leads to repeat FNA 
procedures, futile diagnostic hemithyroidectomies and the associated additional costs. Rapid on-site adequacy assessment (ROSAA) during the FNA procedure provides immediate feedback and allows for repeat aspirates to ensure specimen adequacy. Studies evaluating the added diagnostic value of ROSAA have consistently demonstrated that the procedure decreases the rates of nondiagnostic specimens and false-negative cytology and the number of needle passes found to be necessary [4, 9, 10, 14-17].

Other factors that have been associated with nondiagnostic US-FNA results are the cystic content of a thyroid nodule, poor preparation of slides with smears that are too thick, blood obscuring the visualization of follicular cells, poor specimen fixation or an inadequate staining technique $[1,6,16,18]$. Modified or alternative techniques, such as using a different type and size of biopsy needle or additional liquid-based cytology, are related to better adequacy rates [19-22]. In addition, both experience-based operator dependency and interobserver variance between cytotechnologists and cytopathologists have repeatedly been demonstrated [23-26].

This study was designed to evaluate the adequacy rate of all thyroid US-FNAs at our hospital and to identify factors associated with nondiagnostic cytology. Specifically, we hypothesized that the performance of thyroid USFNA by an experienced radiologist or with additional ROSAA would improve the adequacy rates.

\section{Materials and Methods}

\section{Patient Selection}

With approval by the local Institutional Medical Ethics Committee, all consecutive thyroid US-FNAs in adult patients between 2006 and 2013 at the University Medical Center Utrecht were retrospectively included. Data were extracted from both US and cytopathology reports. Data recorded included the name of the operator, whether ROSAA was performed, the number of aspirates during one procedure, the thyroid nodule US characteristics and the number of clinic visits for repeated US-FNA of the same thyroid nodule. Four groups were used to categorize the 127 operators: 107 radiology residents, 13 radiology fellows, 6 attending radiologists (with 5-20 years of experience) and a separate category for our single, most experienced radiologist (with $>20$ years of experience). US-FNAs were excluded when they concerned residual tissue after previous thyroid surgery.

\section{US-FNA Procedure}

US was performed using a Philips iU22 Ultrasound System (Philips Healthcare, Eindhoven, The Netherlands) with a linear 12 - to $5-\mathrm{MHz}$ transducer. FNA was performed using either a 21-gauge/1.5-inch (BD Microlance ${ }^{\mathrm{TM}} 3$, No. 2) or 23-gauge/1.25inch needle (BD Microlance 3, No. 14; Becton Dickinson and Co., Breda, The Netherlands). If a cytotechnologist was present for
ROSAA, for each needle pass, direct smears were made, air-dried and then stained by the Diff-Quik method. Immediate microscopic review of the slides determined the cytological adequacy based on presence of a minimum of 6 groups of follicular cells, each consisting of 10-15 cells $[2,12,13]$. In the case of an inadequate specimen and if time and the comfort of the patient allowed, an additional aspirate was obtained and ROSAA was repeated. The number of aspirates was registered. Finally, all obtained cytology was submitted to the cytopathology department for definite analysis. If no cytotechnologist was present, direct smears were made, marked and then submitted unstained. Two needle passes were standard procedure for US-FNAs without ROSAA.

\section{Cytologic Assessment}

At the cytology laboratory, May-Grünwald-Giemsa staining was applied to all smears. Any additional residual material, placed in a container of CytoLyt ${ }^{\circledR}$ solution (Cytyc Corp., Marlborough, Mass., USA) during US-FNA, was processed using the Papanicolaou stain. Descriptive pathology reports were drafted for each specimen. Smears that could not be interpreted due to quantitative or qualitative reasons were classified as 'nondiagnostic'. The reports were descriptive and no further distinct diagnostic categories were reported.

\section{Statistical Analysis}

Data analysis was performed using IBM SPSS Statistics (v20.0; IBM Corp., Armonk, N.Y., USA). Contingency tables were constructed to compare the different variables to the cytological outcome, i.e. diagnostic or nondiagnostic. The $\chi^{2}$, Fisher exact and independent-samples $t$ tests were used for categorical data, categorical data plus small sample sizes and continuous or numeric data, respectively. A p value $<0.05$ was considered statistically significant. Multivariate analysis was performed for all factors significant on cross-tabulation. The Wald test was used to reduce the multivariate model until only factors that were independently and significantly associated with the outcome remained.

\section{Results}

In total, 1,381 thyroid US-FNAs (mean maximum nodule diameter $26.7 \pm 13.6 \mathrm{~mm}$ ) were included in the study (table 1). These were performed in 682 patients (86\% females) with a mean age of 53.3 years (SD \pm 14.1 ). Diagnostic cytology was obtained for 892 samples (64.6\%). Benign cytology was reported in 793 (57.4\%) cases, 54 (3.9\%) had cytology of undetermined significance, including atypia and follicular or Hürthle cell proliferations and $45(3.3 \%)$ were suspicious or positive for malignancy.

\section{Cytological Adequacy}

Cytological adequacy was significantly higher with the performance of ROSAA $(309 / 414,74.6 \%)$ than without it (583/967, 60.3\%; $\mathrm{p}<0.001$; table 1$)$. The first and second clinic visits for US-FNA of the same thyroid nodule yielded similar rates of adequate cytology (67.0 vs. $66.2 \%$, re- de Koster/Kist/Vriens/Borel Rinkes/Valk/ de Keizer 
Table 1. Results for all thyroid FNAs

\begin{tabular}{|c|c|c|c|}
\hline & Nondiagnostic & Diagnostic & $\mathrm{p}$ value \\
\hline FNAs performed $(\mathrm{n}=1,381)$ & $35.4(489)$ & $64.6(892)$ & \\
\hline Sex, female & $35.7(424)$ & $64.3(765)$ & 0.627 \\
\hline Age, years & $54.1 \pm 14.1$ & $52.8 \pm 14.0$ & 0.101 \\
\hline \multicolumn{4}{|l|}{ Procedural variations } \\
\hline \multicolumn{4}{|l|}{ Clinic visit for thyroid US-FNA } \\
\hline 1 st & $33.0(249)$ & $67.0(506)$ & \multirow[t]{3}{*}{0.001} \\
\hline 2nd & $33.8(128)$ & $66.2(251)$ & \\
\hline 3rd or more & $45.3(112)$ & $54.7(135)$ & \\
\hline \multicolumn{4}{|l|}{ Operator of US-FNA } \\
\hline Radiology resident & $36.1(338)$ & $63.9(597)$ & \multirow[t]{4}{*}{0.576} \\
\hline Radiology fellow & $29.7(35)$ & $70.3(83)$ & \\
\hline Most experienced radiologist X & $35.8(77)$ & $64.2(138)$ & \\
\hline Other attending radiologists & $34.5(39)$ & $65.5(74)$ & \\
\hline \multicolumn{4}{|l|}{ Rapid on-site adequacy assessment } \\
\hline No & $39.7(384)$ & $60.3(583)$ & \multirow[t]{2}{*}{$<0.001$} \\
\hline Yes & $25.4(105)$ & $74.6(309)$ & \\
\hline \multicolumn{4}{|l|}{ Thyroid nodule characteristics } \\
\hline Maximum diameter, $\mathrm{mm}$ & $25.8 \pm 13.6$ & $27.1 \pm 13.6$ & 0.120 \\
\hline \multicolumn{4}{|l|}{ Nodularity } \\
\hline Solitary & $32.5(102)$ & $67.5(212)$ & \multirow[t]{3}{*}{$0.292^{1}$} \\
\hline Multinodular & $36.4(385)$ & $63.6(672)$ & \\
\hline Unknown & $20.0(2)$ & $80.0(8)$ & \\
\hline \multicolumn{4}{|l|}{ Consistency } \\
\hline Solid & $27.6(47)$ & $72.4(123)$ & \multirow[t]{4}{*}{0.054} \\
\hline Mixed solid-cystic & $36.5(107)$ & $63.5(186)$ & \\
\hline Cystic & $29.8(34)$ & $70.2(80)$ & \\
\hline Unknown & $37.4(301)$ & $62.6(503)$ & \\
\hline \multicolumn{4}{|l|}{ Sonographic appearance } \\
\hline Hypoechogenic & $36.9(58)$ & $63.1(99)$ & \multirow[t]{4}{*}{0.813} \\
\hline Isoechogenic & $28.9(11)$ & $71.1(27)$ & \\
\hline Hyperechogenic & $37.8(14)$ & $62.2(23)$ & \\
\hline Unknown & $35.3(406)$ & $64.7(743)$ & \\
\hline \multicolumn{4}{|l|}{ Homogeneity } \\
\hline Homogenous & $30.8(4)$ & $69.2(9)$ & \multirow[t]{3}{*}{$0.816^{1}$} \\
\hline Inhomogenous & $34.2(119)$ & $65.8(229)$ & \\
\hline Unknown & $35.9(366)$ & $64.1(654)$ & \\
\hline \multicolumn{4}{|l|}{ Increased intranodular vascularization } \\
\hline Yes & $48.2(54)$ & $51.8(58)$ & \multirow[t]{3}{*}{0.006} \\
\hline No & $25.5(12)$ & $74.5(35)$ & \\
\hline Unknown & $34.6(423)$ & $65.4(799)$ & \\
\hline \multicolumn{4}{|l|}{ Intranodular calcifications } \\
\hline Yes & $32.8(44)$ & $67.2(90)$ & \multirow[t]{3}{*}{0.324} \\
\hline No & $26.9(14)$ & $73.1(38)$ & \\
\hline Unknown & $36.1(431)$ & $63.9(764)$ & \\
\hline
\end{tabular}

Values are expressed as \% (n) or mean \pm SD. All variables can be compared according to a diagnostic or nondiagnostic cytology result.

${ }^{1}$ Calculated using the Fisher exact test.

spectively), but the third and subsequent visits less often resulted in a diagnostic specimen $(54.7 \%, \mathrm{p}<0.001)$. Increased intranodular vascularization on Doppler US was associated with a significantly higher nondiagnostic rate $(48.2 \%, \mathrm{p}=0.006)$. Other US characteristics, such as nodule size and consistency, showed no significant associa- tion. Finally, no operator dependency was demonstrated. The mean number of US-FNAs performed by each operator group was 8.7 (range 1-31) for radiology residents, 9.0 (range 1-19) for radiology fellows and 18.8 (range 1-45) for attending radiologists. Our single, most experienced radiologist performed 215 US-FNAs. 
Table 2. Multivariate analysis

\begin{tabular}{|c|c|c|c|}
\hline & $\mathrm{OR}^{1}$ & $95 \% \mathrm{CI}$ & $\mathrm{p}$ value \\
\hline \multicolumn{4}{|c|}{ Clinic visit for thyroid US-FNA } \\
\hline 1st & 1 & ref. & \\
\hline 2nd & 1.01 & $0.77-1.31$ & 0.950 \\
\hline 3rd or more & 1.56 & $1.16-2.10$ & 0.003 \\
\hline \multicolumn{4}{|c|}{ Rapid on-site adequacy assessment } \\
\hline No & 1 & ref. & \\
\hline Yes & 0.55 & $0.42-0.71$ & $<0.001$ \\
\hline \multicolumn{4}{|c|}{ Increased intranodular vascularization } \\
\hline No or unknown & 1 & ref. & \\
\hline Yes & 1.73 & $1.17-2.57$ & 0.006 \\
\hline
\end{tabular}

${ }^{1}$ Adjusted ORs for variables associated with nondiagnostic cytology.

\section{Multivariate Analysis}

Multivariate analysis revealed a significant association with nondiagnostic cytology for $\geq 3$ clinic visits (OR 1.56 , 95\% CI 1.16-2.10), ROSAA (OR 0.55, 95\% CI 0.42-0.71) and strong intranodular vascularization (OR 1.73, 95\% CI 1.17-2.57; table 2).

\section{Number of Needle Passes}

Additionally, a subanalysis was performed of the number of needle passes per procedure. This was only registered for US-FNAs when ROSAA was performed. A mean number of 1.75 needle passes $(\mathrm{SD} \pm 0.86)$ was needed to acquire a diagnostic specimen. With $\leq 3$ aspirates, $72.0 \%(298 / 414)$ of all US-FNAs were diagnostic, while this was $59.7 \%(247 / 414)$ in the case of $\leq 2$ aspirates (fig. 1).

\section{Discussion}

Despite its reliability and cost-effectiveness for distinguishing between benign and malignant thyroid nodules, the nondiagnostic rate of thyroid FNA, which varies from 2 to $34 \%$ in the literature, remains a major clinical issue $[1,2,6-10,19]$. Our study identified multiple factors that were significantly associated with adequacy rate: adequacy increased with ROSAA but decreased with $\geq 3$ clinic visits and with strong intranodular vascularization.

Consistently higher adequacy rates of thyroid FNA with the application of ROSAA have led to recommendations for ROSAA to become routine [4, 9, 10, 15, 16, 27].

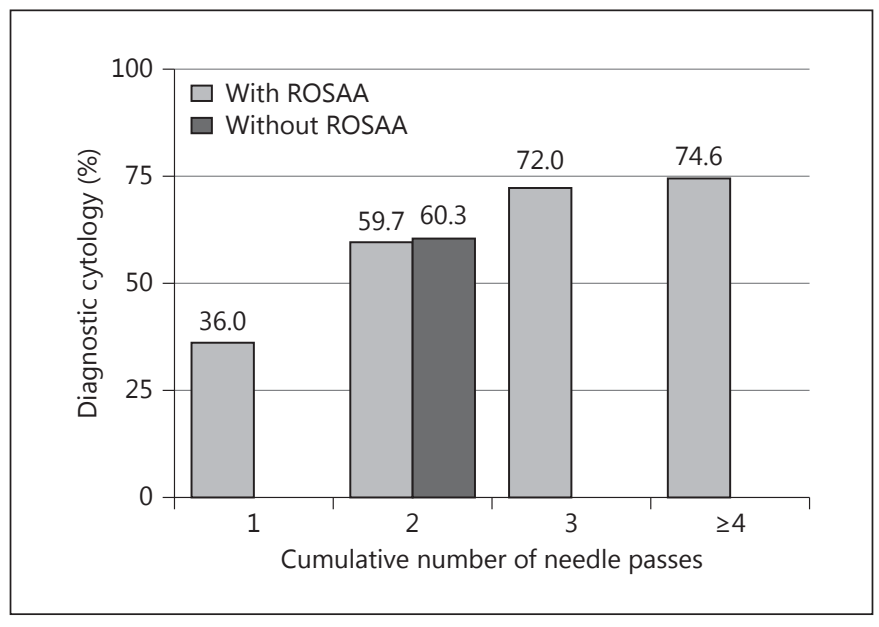

Fig. 1. US-FNA adequacy rate (\%) compared to cumulative number of needle passes.

The absolute $14.3 \%$ (39.7-25.4\%) decrease in nondiagnostic rate that our study demonstrated is greater than the average of $9 \%$ that was reported in a meta-analysis by Witt and Schmidt [28]. This result supports their finding that the increase in adequacy rate with ROSAA correlates with the adequacy rate without ROSAA, and that adequacy improves more when the initial nondiagnostic rate is higher [28].

Before ROSAA was implemented, common practice at our institution was to acquire no more than 2 aspirates per FNA procedure. This resulted in $60.3 \%$ adequate $c y-$ tology. A subanalysis of our results demonstrated that $72.0 \%$ diagnostic specimens were obtained when ROSAA was combined with $\leq 3$ needle passes. This was $59.7 \%$ with ROSAA and $\leq 2$ needle passes, i.e. similar to the former adequacy rate. Without ROSAA, the operating radiologist blindly estimates the number of needle passes needed for adequate cytology. More aspirates then likely result in higher adequacy rates. Studies that performed 4-6 passes as standard protocol have reported nondiagnostic rates as low as 5.5\% [17, 29, 30]. By providing feedback for immediate repeat biopsies and/or redirection of the needle within the thyroid nodule, ROSAA might not only improve adequacy but also decrease the number of needle passes necessary for institutions where protocol prescribes acquiring relatively many aspirates [17]. However, we propose that solely obtaining more aspirates per nodule - without ROSAA - might achieve an equal improvement in adequacy rate. Hereby minimizing additional costs, effort and procedure time, this could be the preferred, more cost-effective option for some institu-
42 
tions, instead of implementing ROSAA. We would recommend performing at least 3-4 needle passes.

We did not demonstrate the influence of operator experience on adequacy rate, despite the vast evidence of operator dependency in the literature on FNA of the thyroid as well as other organs [9, 24, 26]. Ljung et al. [26] defined an experienced operator as one who performs at least 100 FNAs of various body sites per year. For thyroid FNAs, specifically, it has been suggested that an operator has to perform at least 200 procedures before achieving high adequacy rates $[9,24,30]$. As $>100$ operators performed the thyroid US-FNAs in our study (most of them were radiology residents), the individual and general level of experience was limited and may have had a negative effect on the overall diagnostic rate. Even our most specialized radiologist merely performed 215 out of 1,381 thyroid US-FNAs over the course of 8 years, an average of 27 procedures per year, with a success rate similar to the mean (64.2 vs. $64.6 \%)$. Centralizing thyroid FNA procedures to specialized centers and educating a small number of dedicated head-and-neck radiologists could substantially improve adequacy rates by reducing the influence of operator inexperience $[25,26]$.

Our study demonstrated that strong intranodular vascularization on Doppler US was significantly associated with lower adequacy rates. Other studies confirm what we experience in daily practice: blood contamination is one of the main qualitative reasons for nondiagnostic thyroid cytology, and FNA of a hypervascular nodule will often result in bloody aspirates $[4,19]$. Strong intranodular vascularization is rarely mentioned in the literature as a predictor of nondiagnostic cytology [31]. It is, however, described as a possible predictor of malignancy, emphasizing the need for adequate cytology $[7,12,32]$. In contrast to the results of previous studies, other US characteristics, such as consistency or nodule size, were not significantly related to the adequacy rate of thyroid US-FNAs in our study $[6,33]$.

Even though the subsequent clinic visits after the second US-FNA were related to a significantly lower adequacy rate, a third or fourth US-FNA still yielded diagnostic cytology for a substantial $54.7 \%$ of patients in our population. Cost-benefit analysis, consequences and the associated morbidity of surgical intervention as well as the risks associated with delayed treatment for undetected malignancies cause a clinical dilemma of deciding between diagnostic surgery or an additional FNA [34]. A diagnostic hemithyroidectomy is recommended for nodules with a repeatedly nondiagnostic US-FNA and suspicious US or clinical characteristics, because approximately $10 \%$ harbor a malignancy $[5,27]$. Weighing the low risk of aggres- sive thyroid cancer against the roughly $50 \%$ of prevented surgeries upon diagnostic cytology of the third US-FNA, we believe that performing a third US-FNA is beneficial and safe, provided that the time interval between subsequent US-FNAs is appropriately minimalized.

The ultimate goal of this study was to improve the adequacy rate of thyroid US-FNA at our hospital, by first addressing those factors that could improve quality with minor adjustments or minimal additional resources. Moreover, our study shows the value of an institutional assessment of quality of care. We believe that quality assessment of the existing primary diagnostic tools should always be done before more complex measures are added to the diagnostic routine. The resolution might be as simple as performing a few extra needle passes per procedure, leaving additional diagnostics such as molecular testing for BRAF mutations, promising but costly, for the fewer cases that remain nondiagnostic despite improved basic procedures. Guidelines for improvement, like the ones existing for breast cancer, could support this process [35]. Nevertheless, it all starts with a critical assessment of the institution's own performance and acknowledgement of the bottlenecks. The 35\% nondiagnostic rate in our study might not be as exceptionally high as it seems when compared to previously published rates. Large interinstitutional variations indivertibly exist, but publication bias presumably leaves worse rates unpublished and the general nondiagnostic rate higher than the reported average of $17 \%[28,36]$.

The most important limitation of this study was its retrospective design. Data regarding multiple variables were missing for many US-FNAs, mostly US characteristics due to limited reports. The number of needle passes for most of the non-ROSAA US-FNAs was also missing, thereby impeding a full evaluation of our hypothesis regarding the number of needle passes in this subset.

Secondly, even when ROSAA was performed, the USFNA procedure was often discontinued before adequate material had been acquired. Possible reasons for this are time limitations for the procedure, repeatedly bloody specimens, the stress of the patient and disagreement between the on-site and final adequacy assessments. Further research is needed at our institution to analyze the optimal number of needle passes and its presumed relation to the adequacy rate with and without ROSAA.

Potential confounders were addressed during data collection and analysis. Other than the procedural variations that were determined, no differences in US-FNA or cytology assessment procedures were demonstrated throughout the years. A potential confounding factor is that our 
most experienced radiologist was specifically requested as the operator for a number of thyroid FNAs, mostly repeated procedures. Performing the more difficult FNAs may have reduced his adequacy rate. This possible relation could not be objectified due to limited reports.

\section{Conclusions}

This study demonstrated that ROSAA improved the adequacy rate of thyroid US-FNA. When ROSAA is not performed, we recommend obtaining $\geq 3$ aspirates. Diag- nostic cytology is less often obtained from nodules with increased intranodular vascularization or during USFNA that is performed $\geq 3$ times. The adequacy rate of thyroid US-FNA was not operator-dependent in this study. Almost equally important, the results of our study underline the importance of institutional quality assessment of basic diagnostic procedures.

\section{Disclosure Statement}

The authors declare that no conflicts of interest exist.

\section{References}

1 Abraham TM, de las Morenas A, Lee SL, Safer JD: In thyroid fine-needle aspiration, use of bedside-prepared slides significantly increased diagnostic adequacy and specimen cellularity relative to solution-based samples. Thyroid 2011;21:237-242.

$>_{2}$ Gharib H, Goellner JR: Fine-needle aspiration biopsy of the thyroid: an appraisal. Ann Intern Med 1993;118:282-289.

3 Mazzaferri EL: Management of a solitary thyroid nodule. N Engl J Med 1993;328:553-559.

-4 Redman R, Zalaznick H, Mazzaferri EL, Massoll NA: The impact of assessing specimen adequacy and number of needle passes for fineneedle aspiration biopsy of thyroid nodules. Thyroid 2006;16:55-60.

5 Cibas ES, Ali SZ: The Bethesda System for Reporting Thyroid Cytopathology. Thyroid 2009;19:1159-1165.

-6 Alexander EK, Heering JP, Benson CB, Frates MC, Doubilet PM, Cibas ES, et al: Assessment of nondiagnostic ultrasound-guided fine needle aspirations of thyroid nodules. J Clin Endocrinol Metab 2002;87:4924-4927.

7 Carmeci C, Jeffrey RB, McDougall IR, Nowels $\mathrm{KW}$, Weigel RJ: Ultrasound-guided fine-needle aspiration biopsy of thyroid masses. Thyroid 1998;8:283-289.

8 Danese D, Sciacchitano S, Farsetti A, Andreoli M, Pontecorvi A: Diagnostic accuracy of conventional versus sonography-guided fineneedle aspiration biopsy of thyroid nodules. Thyroid 1998;8:15-21.

9 Ghofrani M, Beckman D, Rimm DL: The value of onsite adequacy assessment of thyroid fine-needle aspirations is a function of operator experience. Cancer 2006;108:110-113.

10 Jing X, Michael CW, Pu RT: The clinical and diagnostic impact of using standard criteria of adequacy assessment and diagnostic terminology on thyroid nodule fine needle aspiration. Diagn Cytopathol 2008;36:161-166.
1 Eedes CR, Wang HH: Cost-effectiveness of immediate specimen adequacy assessment of thyroid fine-needle aspirations. Am J Clin Pathol 2004;121:64-69.

12 Cooper DS, Doherty GM, Haugen BR, Hauger BR, Kloos RT, Lee SL, et al: Revised American Thyroid Association management guidelines for patients with thyroid nodules and differentiated thyroid cancer. Thyroid 2009;19: 1167-214.

13 Baloch ZW, Sack MJ, Yu GH, Livolsi VA, Gupta PK: Fine-needle aspiration of thyroid: an institutional experience. Thyroid 1998;8: 565-569.

14 Baloch ZW, Tam D, Langer J, Mandel S, LiVolsi VA, Gupta PK: Ultrasound-guided fine-needle aspiration biopsy of the thyroid: role of on-site assessment and multiple cytologic preparations. Diagn Cytopathol 2000; 23:425-429.

15 Breeze J, Poller DN, Gibson D, Tilley EA, Cooke L, Soar E, et al: Rapid on-site assessment of specimens by biomedical scientists improves the quality of head and neck fine needle aspiration cytology. Cytopathology 2014; 25:316-321.

16 Zhu W, Michael CW: How important is onsite adequacy assessment for thyroid FNA? An evaluation of 883 cases. Diagn Cytopathol 2007;35:183-186.

17 Cengic I, Tureli D, Ahiskali R, Bugdayci O, Aydin H, Aribal E: Thyroid fine needle aspiration biopsy: do we really need an on-site cytopathologist? Eur J Radiol 2014;83:680-683.

18 Massoll NA, Nizam MS, Mazzaferri EL: Cystic thyroid nodules: diagnostic and therapeutic dilemmas. Endocrinologist 2002;12:185198.

19 Cappelli C, Pirola I, Gandossi E, De Martino E, Agosti B, Castellano M: Fine-needle aspiration cytology of thyroid nodule: does the needle matter? South Med J 2009;102:498-501.
20 Rossi ED, Morassi F, Santeusanio G, Zannoni GF, Fadda G: Thyroid fine needle aspiration cytology processed by ThinPrep: an additional slide decreased the number of inadequate results. Cytopathology 2010;21:97-102.

21 Saleh H, Bassily N, Hammoud MJ: Utility of a liquid-based, monolayer preparation in the evaluation of thyroid lesions by fine needle aspiration biopsy: comparison with the conventional smear method. Acta Cytol 2009;53: 130-136.

-22 Samir AE, Vij A, Seale MK, Desai G, Halpern E, Faquin WC, et al: Ultrasound-guided percutaneous thyroid nodule core biopsy: clinical utility in patients with prior nondiagnostic fine-needle aspirate. Thyroid 2012;22:461467.

23 Cibas ES, Baloch ZW, Fellegara G, LiVolsi VA, Raab SS, Rosai J, et al: A prospective assessment defining the limitations of thyroid nodule pathologic evaluation. Ann Intern Med 2013;159:325-332.

24 De Fiori E, Rampinelli C, Turco F, Bonello L, Bellomi M: Role of operator experience in ultrasound-guided fine-needle aspiration biopsy of the thyroid. Radiol Med 2010;115:612618.

25 Berner A, Sigstad E, Pradhan M, Grøholt KK, Davidson B: Fine-needle aspiration cytology of the thyroid gland: comparative analysis of experience at three hospitals. Diagn Cytopathol 2006;34:97-100.

26 Ljung BM, Drejet A, Chiampi N, Jeffrey J, Goodson WH, Chew K, et al: Diagnostic accuracy of fine-needle aspiration biopsy is determined by physician training in sampling technique. Cancer 2001;93:263-268.

27 Haugen BR, Alexander EK, Bible KC, Doherty G, Mandel SJ, Nikiforov YE, et al: 2015 American Thyroid Association Management Guidelines for Adult Patients with Thyroid Nodules and Differentiated Thyroid Cancer. Thyroid 2016;26:1-133. 
28 Witt BL, Schmidt RL: Rapid onsite evaluation improves the adequacy of fine-needle aspiration for thyroid lesions: a systematic review and meta-analysis. Thyroid 2013;23:428-435.

-29 Karadeniz Cakmak G, Emre AU, Tascilar O, Gultekin FA, Ozdamar SO, Comert M: Diagnostic adequacy of surgeon-performed ultrasound-guided fine needle aspiration biopsy of thyroid nodules. J Surg Oncol 2013;107:206210.

30 Sidiropoulos N, Dumont LJ, Golding AC, Quinlisk FL, Gonzalez JL, Padmanabhan V: Quality improvement by standardization of procurement and processing of thyroid fineneedle aspirates in the absence of on-site cytological evaluation. Thyroid 2009;19:10491052.
31 Grani G, Calvanese A, Carbotta G, D’Alessandri M, Nesca A, Bianchini M, et al: Intrinsic factors affecting adequacy of thyroid nodule fine-needle aspiration cytology. Clin Endocrinol (Oxf) 2013;78:141-144.

32 Morris LF, Ragavendra N, Yeh MW: Evidence-based assessment of the role of ultrasonography in the management of benign thyroid nodules. World J Surg 2008;32:12531263.

33 de Meer SGA, Schreinemakers JMJ, Zelissen PMJ, Stapper G, Sie-Go DMDS, Rinkes IHMB, et al: Fine-needle aspiration of thyroid tumors: identifying factors associated with adequacy rate in a large academic center in the Netherlands. Diagn Cytopathol 2012;40(suppl 1):E21-E26.
34 Yeh MW, Demircan O, Ituarte P, Clark OH: False-negative fine-needle aspiration cytology results delay treatment and adversely affect outcome in patients with thyroid carcinoma. Thyroid 2004;14:207-215.

35 Perry N, Broeders M, de Wolf C, Törnberg S, Holland R, von Karsa L: European guidelines for quality assurance in breast cancer screening and diagnosis. Fourth edition - summary document. Ann Oncol 2008;19:614-622.

36 Easterbrook PJ, Berlin JA, Gopalan R, Matthews DR: Publication bias in clinical research. Lancet 1991;337:867-872. 